INVITED PAPER

\author{
James Conant \\ Jconant@uchicago.edu
}

\title{
Wittgenstein's Critique of the Additive Conception of Language
}

\section{Abstract}

This paper argues that Wittgenstein, both early and late, rejects the idea that the logically simpler and more fundamental case is that of "the mere sign" and that what a meaningful symbol is can be explained through the elaboration of an appropriately supplemented conception of the sign: the sign plus something (say, an interpretation or an assignment of meaning). Rather the sign, in the logically fundamental case of its mode of occurrence, is an internal aspect of the symbol. The Tractatus puts this point as follows: "The sign is that in the symbol which is perceptible by the senses." Conversely, this means that it is essential to a symbolto what a symbol is - that it have an essentially perceptible aspect. For Wittgenstein there is no privileged direction of explanatory priority between symbol and sign here: without signs there are no symbols (hence without language there is no thought) and without some sort of relation to symbols there are no signs (hence the philosopher's concept of the supposedly "merely linguistic" presupposes an internal relation to symbols).

Let us start with two quotations - one from Paul Boghossian and one from Wittgenstein. Here is Boghossian:

Well, a word is just an inscription, a mark on paper. Something has got to be done to it by its user for it to get a meaning. That much is clear. (Boghossian 2008, 488)

Here is the one from Wittgenstein:

The decisive movement in the conjuring trick has been made, and it was the very one that we thought quite innocent. (PI, \$308) 
What I wish to show in this paper is that the latter quotation may be taken to be a comment on the sort of thing that happens in philosophy of which the former quotation furnishes a characteristic example. For the former quotation gives voice to the sort of remark that, on the one hand, is apt to strike a contemporary analytic philosopher as not yet involving any interesting philosophical move at all - as merely setting up a philosophical problem without yet having begun upon the task of addressing it; while, one the other hand, it constitutes a lovely example of precisely the sort of thing that Wittgenstein sought to help us to learn to identify as an expression of our inclination to rush past the very moment in which we make the crucial move in the philosophical conjuring trick - a step that he rightly anticipates will strike the Paul Boghossian in each of us, when doing philosophy, as perfectly innocent. ${ }^{1}$

The conception of the linguistic sign that Wittgenstein is concerned in this connection with criticizing - already in the Tractatus and throughout his later writings - is helpfully epitomized in the following slogan of David Hilbert's: "In the beginning was the sign." "That slogan is meant to summarize a central commitment of Hilbert's formalist conception of mathematics: namely, that the signs qua objects are simply given to us in perceptual apprehension. Here is one of his many attempts to spell out exactly what the commitment in question involves:

[A]s a condition for the use of the logical inferences and the performance of logical operations, something must already be given to us in our faculty of representation [in der Vorstellung], certain extra-logical concrete objects that are intuitively [anschaulich] present as immediate experience prior to all thought. If logical inference is to be reliable, it must be possible to survey these objects completely in all their parts, and the fact that they occur, that they differ from one another, and that they follow each other, or are concatenated, is immediately given intuitively. [...]

\footnotetext{
${ }^{1}$ From this point on, the material in this paper represents an attempt to offer a briefer and more accessible version of the discussion found in Part II, Section XIII of the The Logical Alien, ed. Sofia Miguens (Cambridge, MA: Harvard University Press, 2020), 863-947. For a more detailed treatment of these issues, see that volume.

${ }^{2}$ The slogan alludes to Goethe's "In the beginning was the deed"; it can be found in Hilbert's 1922 paper “The New Grounding of Mathematics: First Report” (1922/1996, 1122).
} 
And in mathematics, in particular, what we consider is the concrete signs themselves, whose shape $[\ldots]$ is immediately clear and recognizable. (Hilbert 1927/1967, 464-465 [emphases added])

Hilbert takes some trouble to spell out what is here taken for granted - considerably more trouble in any case than a contemporary philosopher such as Boghossian now, in our post-Hilbertian philosophical age, feels there to be any need to take. The putatively undeniable commitment in question, as formulated by Hilbert, involves the following three presuppositions: (a) the sign qua object is immediately given to us through mere perception in a manner that is prior to all thought, (b) it is possible to survey these objects completely in all their parts as given in such a purely perceptual act, and (c) a successful exercise of this capacity of perceptual intake suffices to allow us to apprehend how signs differ from one another and hence to recognize re-occurrences of a sign as occurrences of the same sign. This paper is concerned with Wittgenstein's criticisms of these presuppositions.

In criticizing such a conception of the sign, the Wittgenstein of the Tractatus already seeks to build on Frege's criticism of Hilbert's formalism. ${ }^{3}$ There are arguably no pages of Frege's that exerted a greater continuous influence on Wittgenstein, throughout the entirety of his philosophical development, than \$\$86-137 of Part II of Frege's The Basic Laws of Arithmetic (Frege 2013, 96-135). Frege, in his critique of the formalist theory of mathematics, charges the formalist's manner of deploying the term "sign" with equivocating between the concept of a mere blot or mark and that of a genuine sign (something that forms a part of a notation). ${ }^{4}$ At one point, this leads Frege to remark, [A]n empty sign [leeres Zeichen] [...] without some content [...] is merely ink or print on paper. [. . .] Really, it

\footnotetext{
${ }^{3}$ The writings of Hilbert that Frege first criticizes in this connection-and that were known to Wittgenstein at the time of writing the Tractatus - stem from an earlier period than those quoted by me immediately above.

${ }^{4}$ For the Fregean background of the Tractarian conception of the sign, passages such as the following are relevant: "What are signs [Zeichen]? I will limit my considerations to structures created by writing or printing upon the surface of a physical body (blackboard, paper) [...]. But we shall not call every such structure a sign-a blot, for instance, would not generally be held worthy of this honor-but only such as serve to designate [bezeichnen], express [ausdrü̈ken], or assert [behaupten] something" (Frege 2013, JS98-100; emphases added; translation modified).
} 
would not be a sign [Zeichen] at all." 5 Though his treatment of the concept of the sign takes its departure from passages in Frege such as this one, what Wittgenstein will want to mean by an expression such as "mere sign" or "empty sign" (or, more notoriously, "dead sign") is something that goes beyond anything that Frege is able to allow for. For Wittgenstein, unlike Frege, "empty sign" need not be an expression that stands for something that does not properly belong to language. There is a phenomenon that it can stand for and to which we need to be able to refer in philosophy, but the phenomenon in question may come properly into view only if we are able to appreciate how it stands for something that is the result of some degree of defect or attenuation in the exercise of our linguistic capacity. Empty signs, for early Wittgenstein, are what we end up with when we unwittingly or wittingly speak (what he calls) nonsense - that is, when we unwittingly fail to confer (or wittingly refrain from conferring) a method of symbolizing upon something that we, as speakers of language, find it natural to strive to apprehend as the outwardly apprehensible aspect of a symbol.

Yet Wittgenstein will also want to show us that what the expression "mere sign" or "empty sign" thereby stands for partakes of the wrong sort of logical generality to comprise a highest common factor across two cases, one of which is a case of something that is not (yet) part of the order of the symbol and one of which is- the highest common factor between a kind of thing whose reoccurrence may be registered through the exercise of a faculty of "mere perception" and a kind of thing whose reoccurrence may be discerned only against the background of an appreciation of how it already forms a part of language. The sign for Wittgenstein partakes of a logical dimension that cannot simply be taken in through an act of Hilbertian immediate perceptual apprehension that is prior to all thought or language.

I must confess that the point of the previous paragraph eluded me for quite some time. Here is how I once tried, in an early paper (Conant 2002, 400), to explain the Tractarian distinction between sign [Zeichen] and symbol [Symbol:

${ }^{5}$ Frege 2013, §95; translation modified. 
Sign: an orthographic unit, that which the perceptible expressions for propositions have in common (a sign design, inscription, icon, grapheme, etc.)

Symbol: a logical unit, that which meaningful propositions have in common (i.e. an item belonging to a given logical category: proper name, first-level function, etc.)

The initial characterization offered here of what a "sign" is does not, taken on its own, betray any obvious misunderstanding of the Tractatus. But the further parenthetical glosses do suggest a somewhat tenuous grip on Wittgenstein's conception of the sign. Let us just focus on one such gloss: "inscription". Well, what is to inscribe something on something? It could mean to write or carve letters on something - where the "letters" are understood to belong to a form of writing or notation. Or it could just mean to carve, engrave, etch, cut, incise, or otherwise cause a series of mere shapes to appear on stone, paper, wood or some other surface mere shapes that might be taken to resemble the shapes of, say, the letters of some alphabet - where the so-called "letters" are now qua the shapes that they are to be regarded as nothing more than mere marks or scratches.

Imagine, while working my way from left to right, I gradually incise the following pair of decorative patterns onto a stone surface - only to learn later that, much to my surprise, it looks to a native speaker of Arabic as if the lower of the two belongs to a different order of pattern than the other - one that he scans in the opposite direction from that in which it was inscribed:

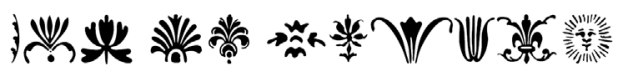

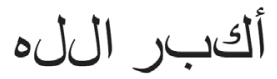

Or to render essentially the same example somewhat easier to deploy for our purposes, imagine that a native Arabic speaker who knows no English, incises a pair of decorative patterns onto a stone surface 
only to learn later that, much to his surprise, it looks to a native speaker of English as if the lower of the two belongs to a different order of pattern than the other:

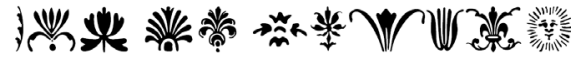

\section{God is great!}

Let us call the following the mere sequence of marks conception of the sign: a "sign" is that which figures as a highest common factor across the following two ways of characterizing the lower pattern: (1) the marks that constitute the design sequence that the inscriber inscribes and (2) the marks that constitute the sentence that the native speaker understands. And let us contrast this, without yet further clarifying it, with what we might call the essentially linguistic conception of the sign: there is no such highest common factor.

On the first of these conceptions, the logically simpler and more fundamental case is that of the sign. The nature of the symbol is to be explained through enhancing our prior conception of the sign: it is the sign plus something - say, the sign used in accordance with certain rules. Assuming that the pattern inscribed by the inscriber in our anecdote does not belong to some standardized pre-existing repertoire of decorative patterns (but rather is one that the inscriber takes himself to have invented on his own), then it looks as if we ought to say - on this conception of the sign (in which it is constituted by nothing more than mere marks) - that any variation in the shape or size of the pattern automatically brings about a change of $\operatorname{sign}(\mathrm{s})$. If we alter it in any way, then what we have is a new sign (or sequence of signs). On this conception of the sign qua mere inscription, a sign is a particular object with a determinate set of geometrically or physically characterizable properties. On a sufficiently literal version of this conception, there are no principles for determining what counts as the repetition of a sign, or for determining where one sign leaves off and the next begins, or even for what counts as merely belonging to the underlying or surrounding surface on which the signs are inscribed as opposed to belonging to the signs themselves. Look at a freshly cut piece of 
wood or a carpet with an arabesque pattern and ask yourself: how many distinct signs or patterns of signs are there on that surface? It is not that you might not be able to make up some way of answering this question. But there is no sense in which, apart from the introduction of some arbitrary stipulations, the question already has a correct answer. One reason the question as posed has no correct answer is the absence of a principle for determining where one sign ends and the next starts; another is the absence of a principle for counting the recurrence of some particular shape as a recurrence of the same sign.

What this helps to bring out is that the concept of a linguistic sign partakes of a form of generality that a mere mark or pattern of incision does not. In learning a language or a form of notation, one learns what counts as a significant repetition - and actually we learn a great deal more. For example, we learn answers to the following questions: What belongs to the signs themselves and what belongs merely to "the space" within which they are inscribed? What constitutes the end of one sequence and the beginning of another? Therefore also: What sorts of marks or arrangements or intervening micro-spaces punctuate or otherwise structure a "sequence"?

The problems that arise here tend to seem to philosophers to be easier to solve than they really are. For example, on a less literal version of the same conception, say, one according to which perhaps shape matters but size does not to the identity of an inscription, one can make some room for a rudimentary idea of what might constitute a principled degree of insignificance in the variation in the appearance - and hence what could count as a "repetition" - of the sign. We could then allow for the possibility, say, that the same merely decorative pattern recurs throughout the following three cases:

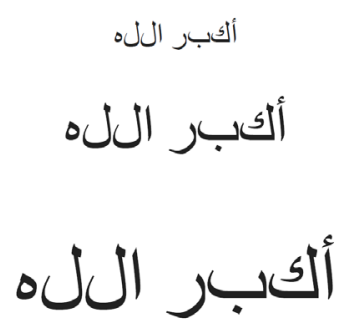


In the same way that we can allow it for the following three cases:

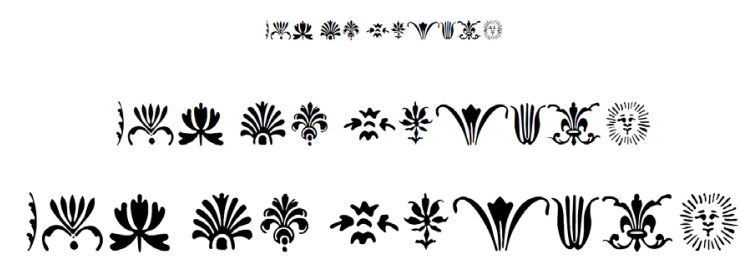

But this will not yet furnish us with the conceptual resources required for accounting for the sense in which the same "sequence of signs" is common to the following three cases:

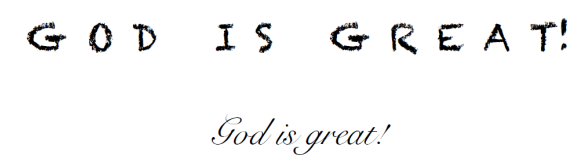

G I I IS G IA EA T!

Appeals to supposedly merely outward forms of resemblance or shared geometrical properties will no longer easily do the trick. The Tractatus teaches that a coherent conception of the unity of these three cases requires a conception of sign that allows us to recognize them as three expressions of the same propositional symbol. This is to reject the idea that the logically simpler and more fundamental case is that of the sign and that what a symbol is can be explained on an appropriately supplemented conception of the sign: the sign plus something. Rather the sign, in the logically fundamental case of its mode of occurrence, is an internal aspect of the symbol: "The sign is that in the symbol which is perceptible by the senses." Conversely, this means that it is essential to a symbol - to what a symbol is - that it have an essentially perceptible aspect. There is no privileged direction of explanatory priority between symbol and sign: without signs there are no symbols (hence without language there is no thought) and without some sort of relation to symbols there are no signs (hence the philosopher's concept of the supposedly merely

\footnotetext{
6 "Das Zeichen ist das sinnlich wahrnehmbare am Symbol" (TLP, 3.32). The German "am" is hard to translate here. A less literal translation that helps bring out the point of the passage would be: "The sign is the sensibly perceptible aspect of the symbol."
} 
linguistic presupposes an internal relation to symbols). But these two forms of dependence are not of the same sort.

Wittgenstein does not seek to invert the order of explanation with which the mere-sequence-of-marks conception works. Rather he seeks to bring out how it is essential to our understanding of the logically fundamental case of the occurrence of the sign that we recognize it as an aspect of a symbol. This requires that the sign partake of the order of generality - or repeatability - of the symbol. Wherever we can recognize a recurrence of the same symbol(s), there is the possibility of a sensibly apprehensible mode of expression thereof that involves the same sign(s). The concept of the sign here required is one of something whose identity is retained across extraordinary variation in the shape, size, font, style, etc. For its determination qua the sign it is, in its logically primary mode of occurrence, does not depend merely on our mere capacity to recognize visible or acoustic appearance properties of something merely physical, but rather on our capacity to recognize reoccurrences of something that belongs essentially to the order of the symbol. When we have difficulty reading someone's handwriting, we are not mastering a new notational system that involves 26 somewhat different but fixed tokens for the letters of the alphabet. Rather, in the logically basic case of the exercise of our capacity for such a form of linguistic apprehension, we apprehend the identity of the signs through recognizing the symbol in them. ${ }^{7}$

What Wittgenstein will mean by an expression such as "mere sign" (or more famously: "dead sign") is something he seeks to show us has the wrong sort of logical generality - repeatability - to be a highest common factor across two cases, one of which is a case of something that is not (yet) part of order of the symbol and one of which is. ${ }^{8}$ Something that is recognizable as a mere sign (in the

\footnotetext{
${ }^{7}$ A similar point holds, as we shall see below, for the phonetic order.

${ }^{8}$ Silver Bronzo seeks to make a similar point about the absence of such a highest common factor. He writes:

It is possible to hold that signs are conceptually dependent on symbols, but in a manner that allows signs to be common to different symbols and leaves room for occurrences of signs that are not occurrences of any symbol. [...] [T] he notion of mere sign is defined as what merely appears to be a symbol, and the generic notion of sign is defined disjunctively as what is either a symbol (i.e., a sign in use) or a mere sign. Symbols and
} 
relevant sense) is a logically defective or attenuated exercise of our capacity to employ signs - one whose very possibility presupposes the prior capacity to employ it as the sensibly perceptible aspect of a symbol. Most contemporary philosophers will be inclined to invert the order of explanation, regarding the problematic mode of occurrence as the logically simpler phenomenon and (what counts for Wittgenstein as) the comparatively less problematic case as requiring that something be added to the sign - something that breathes life into what is otherwise inert.

What is said above about written signs holds equally of spoken ones. An example may help to bring out the point here. When I was a teenager I worked as an English teacher in Japan. My students had all studied the language for at least a decade and were fairly adept at reading but not the least adept at listening to or speaking English. They were neither able to follow a simple conversation between native speakers nor able to say something that a native speaker could recognize straight off as English. I realized that I had no chance of teaching them to speak the relevant "sounds" until they first acquired the ability to hear them. I developed various techniques to help them

mere signs are species of the genus comprising all signs, but such species are not defined in terms of the genus and an independently intelligible differentia. (Bronzo 2017, 1348)

I think it is an unhelpful overstatement to say that a generic notion of the sign is introduced here such that what it is to be a sign for Wittgenstein is disjunctively defined in a certain way. This should seem no less strange than saying that the concept of an animal is really the notion of a sort of being that is properly defined disjunctively as either something that is living or dead. What is right in the thought that the disjunctivist schema may illuminate something here does not turn on the claim that Wittgenstein is operating with some logically complex form of definition. What is right is that the sign-in-use is the logically prior notion. Cases of the employment of a sign that are characterizable in such a way that we are entitled to speak of the occurrence as involving a "mere sign" are always ones that indicate something attenuated or defective in the employment of the sign. A sign in its non-defective employment is a sign-in-use. Hence a mere sign is a sign occurring apart from the sort of context in which it properly has its life. This is all we need to entitle us to Bronzo's central insight:

The sort of use that belongs to a purely formal symbol cannot be specified independently of the notion of a sign that is used to characterize the form but not the content of significant propositions, which in turn is just an abstraction from the notion of a sign that is used to characterize both the form and the content of significant propositions. (ibid., 1350) 
with this. Here is an example of such a technique. I would write the following four words on the blackboard:

(1)roll

(2) roar

(3) loll

(4)lore

The exercise was this: I would say one of the words and the students had to guess which one I was saying. So I would say one of the four and then ask: (1)? Those who thought it was (1) would raise their hands, and so on. For the first hour or so, it did not matter which one of the four I said: $25 \%$ of the students thought it was (1), $25 \%$ thought it was (2), 25\% thought it was (3), and 25\% thought it was (4). This exercise alternated with exercises in which I showed them the difference in the position of my tongue when saying an $l$ (up against the back of my upper teeth) from saying an $r$, then asking them to say each of the four words attending to the position of their tongue as they did so. Then I returned to the exercise of saying one of the four words on the blackboard and asking them to vote. And so on. After about an hour, the word I was actually saying gradually began to garner a somewhat higher percentage of the students' votes than the other three. What I was teaching these students to do was to discern four distinct phonetic English signs out of an acoustic space within which they initially were able to discern only phonemes that they themselves were initially able to produce. We will return to the significance of this latter point in a moment.

The following detail in my anecdote about teaching English in Japan might mislead: the exercise that involved those four English words written on the blackboard was one that could be engaged in without teaching the students what those four English words mean (or even what kinds of logical symbols, or grammatical parts: verbs vs. nouns, they belonged to). But it is crucial that this is the exception and not the rule. For there is no independently available merely phonetic measure of the required degree of discrimination - within the topography of significant phonological contours - apart from an 
appreciation of the relation of the phonetic sign to the communicatively significant act. To participate in this particular exercise, my Japanese students had to learn to discern certain dimensions of significant phonetic difference within the field of the spoken English produced by a language teacher.

Here is a first (and we will later see: inadequate) attempt to say what made the exercise especially difficult for these students: they could not hear the difference between $l$ and $r$. The task led the students to hear four phonetically indistinguishable signs. From a phenomenological point of view, what each of my students initially experienced, when she attended to my respective pronunciations of these four words, was a frustratingly uncooperative speaker: someone who seemed to speak very indistinctly - indeed, so indistinctly that it was hard for the student even to make a reasonable guess at which syllabic units he was attempting to emit.

Boas $(1911,16)$ reports the following about some of the early twentieth-century anthropologists who first began systematically studying American Indian languages:

[E]xamples of American languages have often been brought forward to show that the accuracy of their pronunciation is much less than that found in the languages of the civilized world.

In his diagnosis of the source of this (mis)perception, Boas first observes:

It would seem that this view is based largely on the fact that certain sounds that occur in American languages are interpreted by observers sometimes as one European sound, sometimes as another. (Boas 1911, 16-17)

Boas then presents a far more representative instance of what is really going on in such a case of learning to hear a phonetically alien language than can be made clear by the sort of artificial classroom exercise I cite above (about teaching English to native Japanese speakers). His example illustrates far more accurately the sort of difficulty involved in learning to enter the phonological field of a language very different from one's own: 
[T] he Pawnee language contains a sound which may be heard more or less distinctly sometimes as an $l$, sometimes an $r$, sometimes as $n$, and again as $d$, which, however, without any doubt, is throughout the same sound, although modified to a certain extent by its position in the word and by surrounding sounds. It is an exceedingly weak $r$, made by trilling with the tip of the tongue at a point a little behind the roots of the incisors, and in which the tongue hardly leaves the palate, the trill being produced by the lateral part of the tongue adjoining the tip. As soon as the trill is heard more strongly, we receive the impression of an $r$. When the lateral movement prevails and the tip of the tongue does not seem to leave the palate, the impression of an $l$ is strongest, while when the trill is almost suppressed and a sudden release of the tongue from the palate takes place, the impression of the $d$ is given. The impression of an $n$ is produced because the sound is often accompanied by an audible breathing through the nose. This peculiar sound is, of course, entirely foreign to our phonetic system; but its variations are not greater than those of the English $r$ in various combinations, as in broth, mother, where. The different impression is brought about by the fact that the sound, according to its prevailing character, associates itself either with our $l$, or our $r, n$, or $d$. (Boas 1911, 17)

The recurring phoneme in Pawnee at issue here initially strikes the anthropologist as lacking phonetic determinacy: it seems to hover between the variety of available phonetic options discernible to him - alternating between our $l$, or our $r, n$, or $d$-without itself appearing to be any recurring phonetic element. The relevant recurring phonological unit is, at first, therefore simply inaudible to the anthropologist as a phonetic repeatable - a unit that recurs within his auditory field of sensory apprehension. Yet its actual degree of phonetic variation is not any greater than that of standard English pronunciations of $r$ in various combinations such as broth, mother, where - that is no greater than the degree of variation that constitutes the unity of one of the two recurring units of spoken English that was, at first, simply inaudible to my Japanese students. This allows us to see a little more clearly what the real difficulty is that afflicted my Japanese students. A native English speaker, as we saw, is initially prone to characterize their difficulty this way: they cannot tell the difference between $l$ and $r$. Though not false, this misses the deeper problem: they are unable to discern the bandwidth of phonetic variation in the range of admissible pronunciations of either $r$ or $l$. 
The phonological unity of each of these signs is as phonetically alien to them as a great many of the units of spoken Pawnee initially are to Boas's anthropologists. That which is apparently alien in the other language in such a case can be overcome, only if we first learn to apprehend and master what is initially inaudible (or invisible) in the dimension of what is genuinely alien in the sign.

Unlike Boas's colleagues first studying native American languages, my Japanese students, due to their prior proficiency as readers of written English, go into the exercise with which I present them already equipped with the knowledge that (1) through (4) on the blackboard are four different English words. To say that they know that these are four distinct words is to say that they have (through their familiarity with the written form of English, as well as with a certain amount of spoken English) acquired the general ability to identify recurring units of significance within the language, as well as to discriminate the four words on the blackboard as written signs - as the graphematic counterparts of the four phonetically indistinguishable words. They already know all this - and hence a great deal - well before they are able to distinguish these four words phonetically. This is because my Japanese students were neither learning a first language, nor just beginning to learn a second. This means that though the above example can help to uncover certain philosophical assumptions to which we are prone, it in no way provides an adequate model for understanding what is involved in grasping the general relation of sign to symbol.

Learning to hear and speak a foreign language is not merely a matter of mastering the spoken units of something like a collection of one-syllable sounds. It is a matter of acquiring an appreciation of the range of phonic dimensions within which variation of sound makes a difference to meaning, as well as which variations in accent, stress, intonation, aspiration, etc. issue in shifts of meaning, mood, aspect, tense, etc. In many European languages, a slight shift in intonation can convert an indicative statement into an interrogative utterance. In Mandarin Chinese, what a speaker of English will experience as "the same syllable" is actually something that changes its meaning according to variation in tone. More familiarly to speakers of English: subtle shifts of stress - often difficult for non- 
native speakers to detect - can alter meaning. Consider the differences in pronunciation and concomitant shift of meaning in the following pairs of examples of English words:

\begin{tabular}{|c|c|c|}
\hline \multirow{2}{*}{ produce } & PRO-duce & fruit and vegetables \\
\hline & pro-DUCE & bring forth, create \\
\hline \multirow{2}{*}{ recall } & RE-call & remove from circulation, invite for a second audition \\
\hline & re-CALL & remember, call back to mind \\
\hline \multirow{2}{*}{ console } & CON-sole & computer or stereo screen and/or control panel \\
\hline & con-SOLE & confer solace \\
\hline \multirow{2}{*}{ content } & CON-tent & as opposed to form, wrapping, container \\
\hline & con-TENT & as opposed to discontent, unhappy, dissatisfied \\
\hline \multirow{2}{*}{ converse } & CON-verse & "No P is $\mathrm{S} "$ is the converse of "No S is $\mathrm{P} "$ \\
\hline & con-VERSE & speak, talk, chat \\
\hline \multirow{2}{*}{ default } & DE-fault & setting, position or option to which things revert \\
\hline & de-FAULT & fail to meet an obligation \\
\hline \multirow{2}{*}{ desert/dessert } & DES-ert & e.g., the Sahara \\
\hline & des-SERT & best part of the meal \\
\hline \multirow{2}{*}{ invalid } & IN-val-id & disabled person \\
\hline & in-VAL-id & no longer valid \\
\hline \multirow{2}{*}{ object } & OB-ject & thing, item, entity \\
\hline & ob-JECT & complain, protest \\
\hline \multirow{2}{*}{ refuse } & REF-use & rubbish, garbage \\
\hline & re-FUSE & decline, say no \\
\hline \multirow{2}{*}{ subject } & SUB-ject & area of knowledge, person or thing under discussion \\
\hline & sub-JECT & force someone or something to undergo some treatment \\
\hline
\end{tabular}

Such fateful shifts in stress in English almost always occur from the first to the second syllable of a word or vice versa. That means that shifts in stress, as occur in modern Greek, from the fourth to the fifth syllable of a "word", will go unnoticed by a native English speaker until she has trained her ear to attend for differences in significance that are a function of those sorts of differences in pronunciation.

It is a fascinating and philosophically easily underrated fact that European children learn to babble in ways that involve the utterances of nonsensical strings of phonemes that exhibit the difference between indicative and interrogative intonation. The nonsensical strings of phonemes that Chinese children learn to 
babble exhibit a sophisticated mastery of the Mandarin scale of tones. Greek children babble five-syllable strings of phonemes with a strongly accented final syllable. Children learning English as their first language learn to babble in ways that manifest the capacity sharply to differentiate the strings of phonemes that figure in my teaching exercise - i.e., those that my Japanese adult students of English were unable to differentiate. Indeed, these children master this skill long before they are anywhere near able to master uses of words requiring discriminations of meaning as finely grained as those required to understand the four words that figured in my teaching exercise - hence long before they are able to grasp differences such as those between rolling and rotating, lolling and lingering, lore and myth, roaring and growling. Nevertheless, it would be a mistake to conclude from this that children acquiring mastery of a first language are first just learning their way around a self-standing phonological space, before they engage in acts of linguistic communication or uptake. Rather they are learning to discriminate the topography of the phonological field as they learn to recognize patterns of significant use across recurrences of words such as "mama", "kitty", and "peekaboo" and as they learn themselves to employ these words under various circumscribed primitive occasions of use."

When it comes to learning a first language: just as learning to hear the differences between certain phonemes is not a matter of the child's merely registering certain differences in what she hears and then reproducing them, so, too, mastering a concept is not a matter of the child's merely registering a certain pattern in the use of a word and then (in a sudden and happy leap of interpretation) latching onto "the meaning" of the word. The capacities that the child passively draws on in discriminating the phonetic structure and grasping the point of the use of a word presuppose that the child also autonomously participates in the activities of attempting to pronounce and use some such words herself. Just as learning to produce certain phonetic differences and learning to hear them are interrelated aspects of a single task, so, too, learning to creatively

\footnotetext{
${ }^{9}$ This does not mean that they have - through such incipient achievements of joining sign with symbol - thereby already fully mastered the meaning of the English word "kitty". On this, see Cavell's illuminating discussion of the example of a child acquiring the concept "kitty" (in Cavell 1979, 171ff.)
} 
project words into new contexts and learning to grasp the projections of those same words by others into new contexts are two aspects of a single task. What is even harder to see here is that these two pairs of interrelated capacities - to hear and produce phonemes, on the one hand, and to detect and to project a pattern of use, on the other - are themselves no less intertwined. The capacities one passively draws on in hearing and understanding presuppose that the child actively learns and autonomously participates in the linguistic practice in question: these two dimensions in the acquisition of linguistic autonomy - the attainment of autonomy qua master of the production of the sign (the sensibly perceptible aspect of the sign) and attainment of autonomy qua master of the symbol (the sign in use) - are two dimensions of the actualization of a single capacity.

Philosophers are prone to underestimate what an enormous and specific (though by no means linguistically self-standing) achievement it is on the part of children to learn to babble. Learning to babble in one's first language is a sophisticated achievement, a highly differentiated actualization of the child's general linguistic capacity. This achievement is one of a whole range of preconditions for acquiring the capacity to hear language - a capacity that Quine and Davidson think we start with and whose exercise constitutes the point of departure in any task of language learning.

The latter philosophers tell us that a child begins to learn language by hearing mere sounds (or seeing mere marks) and then assigning interpretations to them - often accompanying this claim with the observation that "it is obvious" that the interpreter has nothing to go on but a mere pattern of sound. ${ }^{10}$ The examples above

10 " $[$ it is $[\ldots .$.$] obvious that the interpreter has nothing to go on but the pattern of sounds$ that the speaker exhibits in conjunction with further events" (Davidson 2001, 13-14). The following is a more careful statement from Quine - one that allows that we need, in learning to understand a spoken language, to learn to separate phonetic signal from acoustic noise: "We form the habit, in hearing the myriad variations of spoken sounds, of treating each as an approximation to one or another of a limited number of norms-around thirty altogether-constituting so to speak a spoken alphabet" (Quine 1969, 90). But this still leaves the following ideas in place: (1) that the thirty or so phonetic signs that allegedly constitute a spoken alphabet are delimited by a set of norms whose range of permissible variation may be discerned apart from any appreciation of their use in communication, (2) that the identification of such phonetic units is prior to the comprehension of their phonologically significant modes of combination (so that a full comprehension of the 
about teaching English and learning Pawnee help to bring to the fore the crucial unstated assumption here: namely, that the relevant power (to discriminate among significant units of sound or shape) comes for free with our non-linguistic powers for sight and hearing - hence comes with those capacities to hear sounds and detects shapes with which we are naturally endowed simply through the proper maturation of our sensory organs. The assumption therefore is that hearing or seeing linguistic signs involves nothing more than the exercise of an unacquired sensory capacity - hence one that is in no way an essentially linguistic capacity. On this conception, no determination of mere powers of sensory apprehension into specifically linguistic capacities (for recognizing the sensibly perceptible aspects of symbols) is required in order to apprehend the relevant shapes and sounds that constitute the perceptibly apprehensible dimension of language.

The artificiality of my above example of a classroom exercise for learning to distinguish four English words may now come into view as involving some rungs on a ladder of elucidation that needed to be thrown away. We have already thrown some of them away, beginning with our reflections on the superiority of Boas's example to my own. Throwing away one such rung allowed us to see that the difficulty that my Japanese students encountered turned out be much more profound than that of merely being unable to distinguish $l$ from $r$. Here was another rung: the example involved a merely local difficulty in discrimination, not the difficulty of acquiring a general power for a certain form of linguistic discrimination. Boas's anthropologists at first have no way of isolating anything as a recurring unit of significance in the Pawnee language, whereas my students already have acquired a rich set of principles for isolating and identifying recurring elements of significance in English. But even Boas's anthropologists speak at least one (other) language before they attempt to learn Pawnee. So now we need to throw away some more rungs.

phonetic contours of such an "alphabet" is prior to the idea of significant speech in the order of comprehension), and (3) that language learning is a matter of first learning one's way around such an alphabet before one starts assigning the noises meanings. 
My example of teaching Japanese adults English is folded within the larger enterprise of imparting and learning a second language. The anecdote helps to bring out certain logical points. It is bound to mislead, however, if certain peculiarities of the structure of that task are read back into the very concept of what it is to acquire language überhaupt. In particular, the philosophical morals that may be drawn from the anecdote about teaching English in Japan will mislead if we continue make a further assumption - one that Quine and Davidson also make, but so do some philosophers who understand themselves to be very critical of them. The further assumption is this: that the character of that which we sensuously apprehend in learning a second language is essentially the same as that which figures in the task of learning a first. To express Wittgenstein's opposed conception in a Kantian idiom: learning a first language involves the actualization - the dawning and maturing - of a power that characterizes the very sort of being that we are, while learning a second involves making a new sort of use of a power that has already achieved actuality in us.

Here is Wilfrid Sellars summarizing what he takes to be one of the important lessons of the opening sections of Wittgenstein's Philosophical Investigations:

[W] hen we picture a child - or a carrier of slabs - learning his first language, we, of course, locate the language learner in a structured logical space in which we are at home. Thus, we conceive of him as a person (or, at least, a potential person) in a world of physical objects, colored, producing sounds, existing in Space and Time. But though it is we who are familiar with this logical space, we run the danger, if we are not careful, of picturing the language learner as having ab initio some degree of awareness - "pre-analytic", limited and fragmentary though it may be -- of this same logical space. We picture his state as though it were rather like our own when placed in a strange forest on a dark night. In other words, unless we are careful, we can easily take for granted that the process of teaching a child to use a language is that of teaching it to discriminate elements within a logical space of particulars, universals, facts, etc., of which it is already undiscriminatingly aware, and to associate these discriminated elements with verbal symbols.

(Sellars 1956, section 30) 
Sellars is right: Wittgenstein thinks that there is a philosophical danger of picturing the child learning her first language in such a way that we ascribe to the child - or a carrier of slabs - the capacity to make the categorial discriminations that are intimately known to us in virtue of our familiarity with a space whose logical topology we have mastered through our having learned to speak our first language. Sellars dubs philosophical views that fall prey to this particular guise of the myth of the given - the fantasy that the topology of logical space could simply be given - as Augustinian. ${ }^{11}$ In so doing, he is thinking of passages from Philosophical Investigations, such as the following:

Augustine describes the learning of human language as if the child came into a strange country and did not understand the language of the country; that is, as if it already had a language, only not this one. Or again: as if the child could already think, only not yet speak. $(P I, \S 32)$

Sellars's identifies the underlying philosophical error of Augustinianism with the idea that there could be "any awareness of logical space prior to, or independent of, the acquisition of language". ${ }^{12}$ To picture the child learning her first language this way is to picture her mastery of the relevant logical space as a highest common factor in her repertoire of capacities prior and posterior to her learning language. But the philosophical rejection of this picture often involves a retreat to a picture in which the idea of a highest common factor still has a role to play. One simply strips down what is taken to comprise the highest common factor in question across the repertoire of capacities already active in the child prior and posterior to her learning her first language.

If "Augustinianism" is to be employed as a general term for classifying the full range of mythological ways of thinking about

\footnotetext{
11 Sellars 1956, section 30. In following Sellars in his employment of the label "Augustinian", I do not mean to thereby endorse any exegetical claim about the writings of St. Augustine. On the contrary, I am inclined to assume that "Augustinianism" in the philosophy of language has roughly as much to do with Augustine as (what gets called) "Cartesianism" in the philosophy of mind does with Descartes or "Kantianism" in epistemology does with Kant.

${ }^{12}$ That is, he identifies it with the denial of what he calls "psychological nominalism" (Sellars 1956, section 31).
} 
language that constitute Wittgenstein's concern above, then a proper characterization of the overall shape of the Augustinian myth needs to be formulated in more capacious terms. It is the myth that any significant aspect of acquiring one's first language could as such resemble the learning of a second language. In broadest outline, it is the myth that the child acquires language as such in the same way that she would acquire a second language - that of a strange country - as if she already were familiar with one language and was now learning her second. Once we have that broader construal of Augustinianism in place, we may relabel the target of Sellars's passage above: Augustinianism about the givenness of logical space. ${ }^{13}$ This allows us to distinguish it from a further species of philosophical confusion that also belongs to the genus Augustinianism - call it Augustinianism about the givenness of the linguistic space of the sign. This is the myth that the acquisition of the very capacity to recognize spoken or written signs as signs could resemble the process of learning the spoken or written signs of a second language - as if the child comes by an understanding of what a sign as such is in just the way she acquires the capacity to discern the signs in use in a strange country - as if she were already familiar with one whole space of linguistic signs and were now learning her way around a second such space.

Sellars's way of ending the passage quoted above might suggest to a reader the following: though it is a mistake to ascribe our logical powers of discrimination to the child, it is not a mistake to ascribe our phonological powers of discrimination to the child. If per impossibile the child were able ab initio to make all the relevant discriminations, then in order to learn language her only remaining task would be to associate the various possible things that words can mean with a set of (what Sellars calls) "verbal symbols" - i.e., phonological signs. ${ }^{14}$ But Wittgenstein thinks that there is yet a further danger in this philosophical neighborhood: namely, that we picture the child learning her first language in such a way that we ascribe to the child - or a carrier of slabs - capacities for discriminating signs that we have in virtue of our familiarity with a space of signs that we have

${ }^{13}$ Or, as I would prefer to call it, employing the terminology introduced above: Augustinianism about the givenness of the logical space of the symbol.

${ }^{14}$ Note: Sellars is here using "symbol" to mean roughly what the Tractatus means by "sign". 
acquired through our having learned to speak a language. The philosophical vicissitudes of this particular fantasy (about what might be merely given to a learner of language) come in for sustained exploration in Philosophical Investigations only once Wittgenstein turns his attention to the rule-following considerations.

One has not fully grasped Wittgenstein's teaching therefore if one does not appreciate that the following pseudo-Sellarsian counterpart to the paragraph from Sellars above also forms a part of the entirety of the Wittgensteinian lesson:

W] hen we picture a child - or a carrier of slabs - learning her first language, we, of course, locate the language learner in a structured phonological space in which we are at home. Thus, we conceive of her as a person (or, at least, a potential person) in a world of recurring phonemes, hearing and producing a spoken alphabet of auditory signs. Though it is we who are familiar with this phonological space, we run the danger, if we are not careful, of picturing the language learner as having ab initio some degree of awareness - "pre-linguistic", limited and fragmentary though it may be - of this same phonological space. We picture her state as though it were rather like our own when placed in a strange place with a lot of background noise. In other words, unless we are careful, we can easily take for granted that the process of teaching a child to discriminate linguistic signs is that of teaching it to discriminate elements within a phonological space of signs of which it is already undiscriminatingly aware.

Many a philosopher who has digested the first Wittgensteinian lesson (that of the paragraph above that Sellars actually wrote) has failed to appreciate how it figures in the Philosophical Investigations as a prelude to this second lesson (that of the pseudo-Sellarsian paragraph immediately above).

What Quine and Davidson assume - in holding that we first learn to discriminate the elements of (what Quine calls) "the spoken alphabet" of a language and only then in a second step start assigning meanings through interpretation - is that the following two cases must have a highest common factor: (i) the case of someone who knows the mere spoken signs of a language and (ii) the case of someone who knows those signs but has also started learning how they symbolize (hence how certain strings of phonemes can be combined in certain recurring ways to constitute units of semantic 
significance). The "mere sounds" (or in the written analogue of this case: the "mere marks") alleged to be common to cases (i) and (ii) comprise, on this picture, a self-standingly intelligible domain of the signapart from that of the symbol. The standard elements of a natural language then must be construed as logical composites, comprising the mere element of the sign common to scenarios (i) and (ii) plus a further symbolizing or signifying factor. The logically most basic case of a word of English, on this picture, is therefore to be understood as comprising two factors: the first factor is the semantically inert phonetic (or graphematic) element, and the second factor is the further element that confers semantic significance on the initially semantically inert element. This picture commits the philosopher to an underlying picture according to which there is a self-standingly intelligible set of terms through which we can characterize the field of "mere signs" of a natural language. ${ }^{15}$ Wittgenstein's favorite term, in his exploration of this picture of language, for the second factor that is supposed to be added to the first is "interpretation". When Wittgenstein says that there is a way of grasping the sign that is not an interpretation ${ }^{16}$, he is denying that every act of understanding language or grasping a rule involves two such acts: one of recognizing the sign or expression of the rule (qua mere sign or expression) and one of subsequently interpreting it. Rather in the logically basic case, recognizing the sign and appreciating its significance are two aspects of a single unitary act.

The unity of language is that of (what Kant calls) a totum, not that of a mere compositum: its division into two ingredient capacities (for recognizing signs and understanding symbols) presupposes the prior unity of the power here under investigation. One does not learn to discriminate the point at which this phoneme shades into that one (and to distinguish these from mere differences in accent or

\footnotetext{
${ }^{15}$ Though most philosophers will provide few details concerning exactly what this set of terms is supposed to involve. The two main original candidates in phonology for spelling out such a picture were acoustic phonetics or motor-phonetics - that one can characterize the field of significantly recurring phonological units either in merely physically acoustic terms or merely in terms of a set of instructions governing the disposition and behavior of the human mouth, larynx, tongue, etc. For Roman Jakobson's seminal trenchant critique of both of these candidates - and hence for the non-reducibility of the phonological dimension of language - see his (1978).
} ${ }^{16}$ PI, 2201. 
pronunciation in the production of one and the same phoneme) simply by attending to such differences as matters of merely phonological interest; rather, one acquires such powers of discrimination through caring about how such differences matter to what one hears and says - hence to one's ability to so much as be able to hear and say it. In learning one's first language, the development of the sensory power to discriminate such differences is, on the one hand, a condition of understanding what others say; while, on the other, an appreciation of how such signs are the perceptible aspects of symbols is a condition of the cultivation of the relevant power of sensory apprehension.

In later Wittgenstein's work, the central term for the sort of something with which the "mere" sign is supposed to be supplemented, in order to redeem it from its supposed condition of semantic inertness, is an "interpretation". The dialectical exploration of this idea culminates in a famous regress and an associated paradox ${ }^{17}$ - the significance of which has been variously construed by readers of Wittgenstein. It is not infrequently claimed by commentators that the central question that animates the relevant stretch of sections in Philosophical Investigations (sometimes referred to as the rule-following considerations) is the following: "What breathes life into dead signs?". Later Wittgenstein does, indeed, present us with various interlocutors who give voice to just such a question, phrased in this way. In this respect, these commentators are not wrong. But as long they attempt to schematize the dialectic that unfolds in these sections as one that is supposed to culminate in Wittgenstein's answer to this question, they will fail to discern the dialectical structure and aim. The interlocutor assumes that what is required for one to be able to recognize a reoccurrence of "it" as a case of "the same sign" (qua dead sign) can be put into place apart from a conception of its correct use. Wittgenstein's aim is to bring out the confusion contained in the interlocutor's very way of posing the question that initiates the ensuing dialectic. Hence a fundamental target - a crucial moment in the philosophical conjuring trick that is apt to strike us as perfectly innocent - in these sections is precisely the idea that there is a highest logical common factor across a field

${ }^{17} P I, \$ \$ 198,201$. 
of incised marks and squeaked-out noises (marks and noises that are not yet language) and a field of genuine linguistic activity - that there is a highest common factor across the case of the dead sign qua mere sound or shape and the case of the sign qua that which has its life in use.

In other cases in which we speak about something's being dead (say, a corpse), we presuppose a prior comprehension of the category of life - of the logical priority of an understanding of its being alive to the case in which we take ourselves to apprehend that "it" is now in the unhappy condition of no longer being alive. This is crucial to what Wittgenstein seeks to bring out with his paradoxical rhetoric about dead signs, breathing life into them, use as the life of the sign, etc. ${ }^{18}$ It is altogether striking how readily the contemporary analytic philosopher will adopt this rhetoric without the slightest sense of paradox. Wittgenstein has taught us, they will say, that the fundamental problem of the philosophy of language (or of rule following, or of normativity, and so on) is the problem of how it is so much as possible to breathe life into dead signs. The happy acquiescence in this idiom appears to allow for the idea that a sign is the sort of thing for which an understanding of what it is for it to be dead is logically prior to an understanding of what it is for it be alive. ${ }^{19}$ Theologically speaking, an understanding of what it is to turn a dead body into a living one is not an inquiry into the general concept of life, but rather a departure into a very specialized nonbiological field of inquiry. It presupposes the rather remarkable (and, apart portrayals of the miracle of Lazarus or the fate of the righteous on judgment day, seldom instantiated) concept of resurrection. We can reformulate the main point here therefore as follows: standard readings of Wittgenstein seek a theory of the resurrection of "meaning" (or "normativity" or "guidance" or "agreement in judgment"), without first inquiring into (as Wittgenstein himself

\footnotetext{
${ }^{18}$ See, e. g., PI, $\$ 432$.

${ }^{19}$ If a use-theory of meaning is a theory that seeks to answer the question "what breathes life into the dead sign?", the idea of such a theory figures in Wittgenstein's work as a target, not - as is often contended - as part of his doctrine.
} 
seeks to do) what it is about their own starting assumptions in philosophy that appear to have given rise to its death. ${ }^{20}$

\section{Coda: "The Linguistic Turn"}

The expression "the linguistic turn" is often used to gesture at the idea that language, over the course of the twentieth century, acquired a new and central significance for philosophy. What kind of significance? If the expression is understood to denote an intellectual revolution through which a specialized subfield of philosophy moved to its center (replacing epistemology or metaphysics or something else) - and hence "language" (instead of "knowledge", "thought" or "being" or something else) became philosophy's foremost, or at least first, object of investigation - then such an understanding (of what constitutes the supposed "turn") accurately reflects a widely disseminated narrative regarding a putatively continuous line of historical development within the analytic tradition of philosophy. It, no doubt, accurately portrays $a$ line of development within that tradition. Wittgenstein is often to be taken to be one of main figures spearheading that development. Such an account of Wittgenstein's place in the history of analytic philosophy is incompatible with a proper appreciation of what he means when he says that the life of the sign can be seen only in its use - and hence that to imagine a language is to imagine a form of life.

If one wants to use the expression "the linguistic turn" to indicate a revolution Wittgenstein himself seeks to effect in our understanding of the centrality of language to philosophical reflection, then it needs to stand for something very different than just suggested in the previous paragraph. It needs to be understood as standing for the idea that we, who do philosophy, are an fond speaking beings - so that the capacity that we exercise in doing

\footnotetext{
${ }^{20} \mathrm{Ed}$ Minar is after a similar point when he writes: "[Wittgenstein] is not thinking of life as a force that closes the gap [between sign and application]; rather, he questions what one has to have done to the sign — as the sign it is, in its use - to have killed it, to have come to think that it must be resurrected. In other words, he questions the role that the life-giving ingredient would play" (Minar 2011, 28).
} 
philosophy is an essentially linguistic one. ${ }^{21}$ On this conception, language forms both the essential medium of philosophical activity and a non-accidental obstacle to the self-understanding that it seeks.

Such a linguistic turn does not seek in any way - even provisionally - to narrow the scope of philosophy's concern, but always only its mode. Just a few pages into his Metaphysics, Aristotle raises the question whether "philosophy" and "logic" name two distinct (if perhaps interrelated) forms of inquiry, as may initially appear to be the case, or whether they really constitute two aspects of one inquiry. Early Wittgenstein seeks to recover a version of the latter sort of vision - one according to which "philosophy" and "logic" and "language" name three aspects of one investigation through his manner of identifying logic with "the logic of our language" and misunderstandings thereof with philosophy. An expression such as "linguistic philosophy" on a properly post-Wittgensteinian understanding of what it ought to mean, ought never to indicate an effort to restrict what initially falls within philosophy's purview (to, say, primarily "linguistic matters" as opposed to primarily epistemological or logical or ethical ones), but rather a radical transformation in the understanding of what language is, so that it comes to permeate every aspect of any investigation in which we seek philosophical understanding.

On this understanding of language's centrality to philosophy's ends, philosophical reflection remains no less focally concerned than before with difficulties that arise when we reflect upon what knowledge, thought, self and world are, but its mode of concern with these problems, through its mode of concern with language, is transformed. We come to appreciate how any act of philosophical reflection involves a reflective exercise of an essentially linguistic capacity. Linguistic signs do not figure in Wittgenstein's philosophical writing as a self-contained realm of phenomena we look at - by looking at, say, mere sounds and marks - and, in so doing, away from ourselves or the world and hence away from our forms of thought, agency and life. Rather getting our forms of

${ }^{21}$ The question of what it means fully to take the linguistic turn in philosophy - and why the one to be found in Frege is only partial - constitutes a longstanding topic of shared interest and conversational exchange between Irad Kimhi and me. For his own treatment of it, see Kimhi (2019). 
mindedness, practice and vital activity into view requires getting our life with language - our everywhere linguistically shaped life, permeating even our powers of perception - into view. This sort of a linguistic turn essentially involves a struggle against confusions regarding knowing, thinking, and being that have their source in our confused relation to the very signs that we cannot help but call upon in philosophizing. On this conception of what "the turn" involves, the attainment of philosophical clarity turns on the achievement of a perspicuous representation of the relations of signs to symbols and vice versa - hence the task becomes one of displaying the true dimensions of logical identity in signs qua symbols across the varieties of contexts of use from which they draw their life.

For all of the differences between early and later Wittgenstein, they each seek to initiate the latter sort of linguistic turn in philosophy (in which the limits of language and those of philosophy coincide), never the former (which gives pride of place to the philosophy of language conceived as a specialized field of inquiry within philosophy as a whole ${ }^{22}$ ). No version of Wittgenstein, properly understood, ever evinces any interest (except as an intermittent target of certain sorts of criticism) in a conception of philosophy according to which "language" constitutes a privileged self-contained object of philosophical investigation - one whose workings and nature may be brought into view before and apart from the struggle to attain clarity regarding the fundamental problems (surrounding thinking and being, self and world, activity and passivity, sensation and thought, assertion and expression, the first person and the third person, I and you, and so on) with which philosophy has long struggled.

\footnotetext{
${ }^{22}$ This is not to say that there is no such thing as philosophy of language so conceived, or that there should not be such a thing, or that one should preferably not pursue it, or that there is not much one can learn from it, or that it cannot draw on things Wittgenstein says for its own purposes - it is only to say that Wittgenstein himself never pursues a form of inquiry that he himself understands to belong to philosophy of language so conceived.
} 


\section{References}

Boas, F., 1911. "Introduction". Handbook of American Indian Languages, Vol. 1 (in Bureau of American Ethnology, Bulletin 40). Washington: Government

Print Office; Smithsonian Institution, Bureau of American Ethnology.

Boghossian, P., 2008. "Epistemic Rules". Journal of Philosophy 105.

Bronzo, S., 2017. 'Wittgenstein, Theories of Meaning, and Linguistic

Disjunctivism". European Journal of Philosophy 25, no. 4.

Cavell, S., 1979. The Claim of Reason (New York: Oxford University Press).

Conant, J., 2002. "The Method of the Tractatus". In: E. H. Reck, ed., From

Frege to Wittgenstein: Perspectives on Early Analytic Philosophy. Oxford:

Oxford University Press, 374-462.

Davidson, D., 2001. "First Person Authority". In: D. Davidson, Subjective, Intersubjective, Objective. Oxford: Oxford University Press.

Frege, G., 2013. Basic Laws of Arithmetic, trans. P. A. Ebert and M. Rossberg. Oxford: Oxford University Press.

Hilbert, D., 1922/1996. "The New Grounding of Mathematics: First Report". In: W. Ewald, ed., From Kant to Hilbert: A Source Book in the Foundations of Mathematics, Vol. II. Oxford: Oxford University Press. Hilbert, D., 1927/1967. "The Foundations of Mathematics". In: J. van Heijenoort, ed., From Frege to Gödel. Cambridge, MA: Harvard University Press.

Jakobson, R., 1978. Six Lectures on Sound and Meaning. Cambridge: MIT Press.

Kimhi, I., 2019. Thinking and Being. Cambridge, MA: Harvard University Press.

Minar, E., 2011. 'The Life of the Sign: Rule-Following, Practice, and Agreement". In: O. Kuusela and M. McGinn, eds., The Oxford Handbook of Wittgenstein. Oxford: Oxford University Press.

Quine, W. V. O., 1969. “Epistemology Naturalized”. In: W. V. O. Quine, Ontological Relativity and Other Essays. New York: Columbia University Press.

Sellars, W., 1956, Empiricism and the Philosophy of Mind. Minneapolis: University of Minnesota Press.

Wittgenstein, L., 1922. Tractatus Logico-Philosophicus. London: Kegan Paul. [TLP]

Wittgenstein, L. 1953/2009. Philosophical Investigations. Eds. P. M. S. Hacker and J. Schulte, trans. G. E. M. Anscombe, P. M. S. Hacker and J. Schulte. New York: Wiley. [PI] 


\section{Biographical note}

James Conant is Chester D. Tripp Professor of Humanities, Professor of Philosophy, and Professor in the College at the University of Chicago, as well as Humboldt Professor at the University of Leipzig. 